\title{
Práticas de ensino de leitura e escrita no Programa Alfa e Beto: entre estratégias e táticas ${ }^{1}$
}

\author{
Alexsandro da Silva \\ Universidade Federal de Pernambuco
}

\section{Resumo}

Este artigo tem o objetivo de analisar as práticas de ensino de leitura e escrita de duas professoras que participavam do Programa Alfa e Beto e como essas práticas se relacionavam ou não com a proposta do Programa. Utilizamos, como procedimentos metodológicos, a observação participante e a entrevista semiestruturada, cujos dados foram analisados por meio da análise de conteúdo. Os resultados evidenciaram que, apesar de as práticas das professoras serem organizadas em torno do livro didático do Programa, elas (re)inventavam em seu cotidiano outras maneiras de fazer e acrescentavam outras propostas e materiais que não correspondiam às prescrições a que estavam submetidas.

Palavra chave: Programa Alfa e Beto. Alfabetização. Práticas cotidianas.

\section{Practices of teaching reading and writing in the Alfa and Beto Program: between strategies and tactics}

\section{Abstract}

This article aims to analyse the practices of teaching reading and writing of two teachers who participated in the Alfa and Beto Program and whether or not these practices related to the proposed Program. We utilized, as methodological procedures, participant observation and the semi-structured interview, whose data were analysed using content analysis. The results showed that, although the teachers' practices were organized around the program's textbook, they reinvented in their daily lives other ways to make and added other proposals and materials that did not correspond to the submitted requirements.

Keywords: Alfa and Beto Program. Literacy. Daily practices. 


\section{Prácticas de enseñanza de lectura y escritura en el Programa Alfa y Beto: entre estrategias y tácticas}

\section{Resumen}

Este artículo tiene el objetivo de analizar las prácticas de enseñanza de lectura y escritura de dos profesoras que participaban del Programa Alfa y Beto, y cómo esas prácticas se relacionaban o no con la propuesta del Programa. Utilizamos como procedimientos metodológicos la observación participante y la entrevista semiestructurada, cuyos datos fueron analizados por medio de análisis de contenido. Los resultados evidenciaron que, a pesar de las prácticas de las profesoras ser organizadas en torno del libro didáctico del Programa, ellas reinventaban en su cotidiano otras maneras de hacer y añadían otras propuestas materiales que no correspondían a las prescripciones a que estaban sometidas.

Palabras clave: Programa Alfa y Beto. Alfabetización. Prácticas cotidianas.

Assim, o bom é que vem as atividades, não é? A gente tem o livro, a gente tem o caminho. Chega naquele dia, sabe o que vai fazer (PROFESSORA A, 2011 ).

Bom, a gente tem que seguir o que eles mandam, não é? Aí, assim, eles mandam a gente fazer e a gente faz como acha melhor (PROFESSORA B, 2012).

\section{Introdução}

Desde o início dos anos 80 do século XX, os métodos tradicionais de alfabetização e as cartilhas que os concretizavam foram objeto de inúmeras críticas, sobretudo devido aos pressupostos que os sustentavam: a língua escrita era concebida como um código de transcrição gráfica das unidades sonoras, que seria aprendido por meio da repetição e da memorização; os aprendizes eram vistos como seres que nada sabiam sobre a escrita e que só seriam autorizados a ter contato com textos "de verdade", na escola, quando estivessem alfabetizados; e, finalmente, o professor era tratado como um mero executor de passos a serem rigidamente seguidos.

Essa posição crítica em relação aos métodos tradicionais não implica, no entanto, uma negação das questões metodológicas em si, como se elas 
remetessem, por si sós, a um ideário tradicional de alfabetização. Como observa Soares (2004), sem proposições metodológicas claras, corremos o risco de ampliar o fracasso escolar das crianças no acesso ao mundo da leitura e da escrita. Essas proposições metodológicas não podem prescindir, todavia, de contribuições atualmente disponíveis nesse campo, as quais apontam que as metodologias de alfabetização precisam contemplar tanto o ensino do sistema escrita alfabética, quanto das práticas sociais de leitura e escrita.

Considerando essas discussões, desenvolvemos uma pesquisa que teve como objetivo analisar as propostas metodológicas para o ensino da leitura e da escrita presentes em materiais didáticos de um programa não governamental que se destina a alfabetizar crianças por meio do método fônico lo Programa Alfa e Beto) e as práticas de alfabetização de professores que participavam desse Programa. Neste artigo, apresentaremos a análise das práticas de ensino de leitura e escrita de professoras alfabetizadoras que participavam do referido Programa e como as suas práticas se relacionavam ou não com a proposta dele.

Tendo em vista esse objetivo, apresentaremos, inicialmente, algumas reflexões teóricas tanto sobre os métodos tradicionais ${ }^{2}$ de alfabetização e as mudanças ocorridas nesse campo, a partir dos anos 1980, quanto sobre as práticas cotidianas dos professores na sala de aula. Em seguida, após situarmos o caminho metodológico da pesquisa, discutiremos os principais resultados do estudo, bem como teceremos algumas considerações finais.

\section{Os métodos tradicionais de ensino da leitura e da escrita e as mudanças no campo da alfabetização}

Durante décadas, especialmente até os anos 70 do século XX, o ensino da leitura e da escrita era tido exclusivamente como uma questão de método (MORTATTI, 2000; SOARES, 2004). No Brasil, assim como em outros países, instaurou-se uma acirrada disputa entre métodos de alfabetização, que se expressou, principalmente, no embate entre os chamados "métodos sintéticos", que procediam das "partes" para o "todo", e os "métodos analíticos", que adotavam o caminho inverso: do "todo" para as "partes".

Os "métodos sintéticos" tomavam como ponto de partida a letra (método alfabético ou da soletração), o fonema (método fônico) ou a sílaba 
Práticas de ensino de leitura e escrita no Programa Alfa e Beto: entre estratégias e táticas

(método silábico ou da silabação), que, por meio de um processo de síntese, eram combinados para constituição de unidades linguísticas maiores (palavras, frases e textos). Já os "métodos analíticos" (ou globais), ao contrário dos sintéticos, partiam de unidades maiores da língua: palavra (método da palavração), frase (método da sentenciação) e texto (método de contos ou das historietas). Nesses métodos, as palavras, as frases ou os textos eram decompostos, por meio de um processo de análise, em unidades linguísticas menores (frases, palavras, sílabas, fonemas/letras).

Como observaram Chartier e Hébrard (1990), em cada grande etapa da história do ensino da leitura, os diferentes métodos foram ordenados em sistemas de oposição binária e cada um deles é herdeiro dos sistemas de oposição anteriores que eles próprios contribuíram para que fossem esquecidos. Essa tensão entre "antigos" e "modernos" também pode ser observada na história da alfabetização no Brasil, pois, conforme ressalta Mortatti, em cada um dos momentos dessa história, tornou-se

[...] necessário produzir uma versão do passado, e desqualificá-lo, como se se tratasse de uma herança incômoda, que impõe resistências à fundação do novo, especialmente quando a filiação decorrente (embora, muitas vezes, não assumida) da tradição atuante no presente ameaça fazer voltarem à cena os mesmos personagens do passado, que seus herdeiros desejam esquecer, rever ou aprimorar (MORTATTI, 2000, p. 299).

A partir, principalmente, da década de 80 do século XX, os métodos tradicionais de ensino da leitura e da escrita e as cartilhas que os concretizavam foram objeto de inúmeras críticas, em decorrência, sobretudo, de mudanças conceituais no campo da alfabetização. Tais mudanças, impulsionadas, especialmente, pela teoria da psicogênese da escrita, desenvolvida por Emilia Ferreiro e colaboradores (cf. FERREIRO; TEBEROSKY, 1999; FERREIRO, 1995), deslocaram a discussão sobre o "como se ensina" para o "como se aprende" (MORTATTI, 2000; SOARES, 2004), instaurando um movimento de "desmetodização da alfabetização" (MORTATTI, 2000).

A teoria psicogenética da escrita provocou uma verdadeira revolução no campo da alfabetização, alterando radicalmente a concepção que se tinha sobre como a criança aprendia a ler e escrever. Se antes a alfabetização era vista como uma aprendizagem meramente perceptivo-motora, isto é, como a 
aquisição de um código de transcrição da fala, que seria aprendido por meio da repetição e memorização, a partir desse momento, ela (a alfabetização) passou a ser concebida como uma construção conceitual, isto é, como um processo de compreensão de um sistema de representação (notação) dos segmentos sonoros das palavras.

É sobretudo na década de 90 do século XX que começou a se difundir, no Brasil, um outro conjunto de estudos que também teve um importante impacto no campo da alfabetização. Trata-se dos estudos sobre letramento, entendido como o desenvolvimento de comportamentos e habilidades de uso competente da leitura e da escrita em práticas sociais diversas (SOARES, 1998). Apoiando-se nesse conceito, alguns pesquisadores, como Soares (1998), propõem que o ideal seria alfabetizar letrando, isto é, ensinar a ler e a escrever no contexto das práticas sociais de leitura e escrita. Assim, é imprescindível que tanto as atividades de reflexão sobre o sistema escrita alfabética e suas convenções, quanto as práticas sociais da leitura e da escrita estejam presentes em sala de aula.

Apesar das grandes contribuições aportadas pela teoria da psicogênese da escrita e pelos estudos sobre letramento para o campo da alfabetização, é preciso reconhecer que as apropriações delas nos meios acadêmicos e educacionais parecem ter contribuído - seja pela ênfase no "como se aprende", seja pela relevância maior atribuída à imersão da criança em práticas sociais de leitura e escrita - para o que Soares (2004a) designou de "desinvenção da alfabetização", quer dizer para a perda da especificidade desse processo, que, além de apresentar as facetas psicológica, psicolinguística e sociolinguística, é de natureza essencialmente linguística ISOARES, 2004).

Nessa perspectiva, a alfabetização passou a ser vista como um processo espontâneo, que ocorreria por meio do contato com textos e dispensaria um ensino sistemático das propriedades e convenções da escrita alfabética. Soares adverte que é "[...] como se realmente pudesse ocorrer de forma incidental e natural a aprendizagem de objetos de conhecimento que são convencionais e, em parte significativa, arbitrários - o sistema alfabético e o sistema ortográfico" (SOARES, 2004a, p. 14).

Como uma reação à "desinvenção da alfabetização", surgiram, no limiar do século XXI, no Brasil e em outros países, propostas de retorno aos 
métodos tradicionais de alfabetização, especialmente do método fônico, um método sintético de alfabetização no qual cada grafema é aprendido como um fonema, que, junto a outro fonema, pode formar sílabas e palavras (FRADE, 2007). Esse retorno aparece, muitas vezes, associado a interesses mercadológicos (venda de livros, programas de alfabetização, etc.), associados à promessa de reverter o problema do baixo desempenho dos alunos em leitura e escrita, cuja responsabilidade é atribuída pelos defensores desses métodos à suposta difusão do "construtivismo" nas escolas brasileiras.

Segundo Mortatti (2010), o retorno dos métodos fônicos no cenário contemporâneo brasileiro configura um processo de "remetodização da alfabetização", o qual pode ser assim caracterizado:

Trata-se da reposição/atualização de um novo/velho discurso, já fartamente conhecido e utilizado ao longo da história da alfabetização no Brasil por aqueles que [...] buscaram convencer seus contemporâneos de que eram portadores de nova, científica e definitiva solução para os problemas da alfabetização no país (MORTATTI, 2010, p. 334).

Esse movimento de retorno aos métodos fônicos relaciona-se, em seu sentido mais perigoso, ao que Soares (2004a) designou de "reinvenção da alfabetização", que, para ela, não pode representar, como tem acontecido, um retrocesso - o retorno aos antigos métodos -, mas, sim, uma necessária recuperação das especificidades do processo de alfabetização, sem desconsiderar as contribuições teóricas hoje disponíveis nesse campo.

Em função do objetivo dessa pesquisa, que consiste em analisar as práticas de ensino da leitura e da escrita de professores que participaram de um programa de alfabetização que tem como suporte o método fônico, apoiar-nos-emos também nas teorizações sobre as práticas docentes cotidianas, por entendermos que tais discussões são fundamentais para a compreensão do nosso objeto de estudo.

\section{As práticas cotidianas dos professores na sala de aula}

Durante muito tempo, especialmente até os anos 70 do século XX, acreditou-se que os professores simplesmente reproduziam (ou deveriam reproduzir) 
os conhecimentos e as orientações a que tinham acesso. Contrariamente a essa perspectiva, compreendemos que os docentes reelaboram, recriam e reinventam o seu trabalho cotidiano, a partir de suas experiências anteriores.

Como esclarece Certeau (2012), os homens não são meros consumidores das produções culturais, pois se apropriam delas, reinventando-as em seu cotidiano por meio de "táticas de consumo". Segundo Sarti (2008), nessa perspectiva, "o consumo cultural revela-se como um espaço de produção de sentidos, uma produção silenciosa que possibilita que os sujeitos, por meio de seus afazeres mais ordinários, não estejam destinados à passividade e à reprodução" (SARTI, 2008, p. 49).

Apoiando-nos nos conceitos de "estratégia" e "tática", elaborados por Certeau (2012) para explicar os processos de invenção do cotidiano, entendemos que os professores podem, diante das "estratégias" - "cálculo lou a manipulação) das relações de forças que se torna possível a partir do momento em que um sujeito de querer e poder (uma empresa, um exército, uma cidade, uma instituição cientifica) pode ser isolado" (CERTEAU, 2012, p. 99 e 100) - (re)construir suas práticas de ensino por meio de "táticas" - "[...] ação calculada que é determinada pela ausência de um próprio".

Chartier (2005), ancorando-se na teoria do cotidiano de Certeau (2012), analisa com maestria ação docente em meio a "estratégias" e "táticas", esclarecendo que

[...] todo mundo sabe que as culturas profissionais se transmitem sempre de boca a boca, no curso dos encontros e das experiências. Estas artes de fazer se transmitem a despeito das hierarquias, que preferem ignorá-las. Por vezes elas as denunciam ou as combatem como tantas rotinas conservadoras: os antigos ensinam aos novos como interpretar as injunções dos superiores hierárquicos sem entrar diretamente em conflito com eles, como vestir as práticas antigas com as palavras dos novos discursos oficiais, como lidar com prescrições sentidas como "impossíveis". Eles sabem também como fazer coisas novas com o velho, inovar para responder a situações não previstas pelos textos e que, no entanto, precisam ser assumidas (CHARTIER, 2005, p. 24).

Como observa Weisser (1998), os professores modificam, ajustam ou, até mesmo, "desviam" os discursos científicos estabelecidos, a fim de construir, progressivamente, um repertório de gestos profissionais que resultam de 
Práticas de ensino de leitura e escrita no Programa Alfa e Beto: entre estratégias e táticas

influências múltiplas. Essa "tradução" revela que os professores reconstroem e adequam ao seu trabalho cotidiano os conhecimentos e as orientações a que têm acesso, mantendo, apenas, aquelas que podem ter um "valor de uso" nas práticas.

Essa constatação parece evidenciar, tal como observou Chartier (2000, 2007), que as inovações didáticas são escolhidas, testadas, mantidas ou abandonadas pelos professores a partir de critérios práticos e não teóricos. Sendo assim, as inovações são incorporadas apenas quando contribuem para uma melhor organização do trabalho pedagógico. Caso contrário, são adaptadas ou mesmo descartadas, principalmente quando envolvem um aumento de trabalho e uma perda de eficiência. Em outras palavras,

Os professores [...] geralmente ignoram as informações validadas cientificamente, elaboradas pelos pesquisadores distantes do campo, publicadas segundo as regras em vigor nas revistas especializadas, mas não diretamente utilizáveis na sala de aula. Entre as inovações didáticas, eles buscam em princípio aquelas que sejam capazes de entusiasmar as crianças e de combater 0 fracasso escolar (CHARTIER, 2007, p. 186).

Em consonância com essa autora, Tardif (201 1 ) esclarece que os professores retraduzem a sua formação e a ajustam ao seu trabalho cotidiano, eliminando o que parece inútil ou sem relação com a realidade vivida e conservando apenas o que pode servir de alguma maneira em seu trabalho. Nessa perspectiva, esse autor compreende que é a experiência que valida ou não os saberes adquiridos anteriormente ao exercício da prática docente cotidiana ou fora dela. Esses saberes experienciais, que são provenientes da experiência na profissão, na sala de aula e na escola, constituem, de acordo com o autor supracitado, um conjunto de representações a partir das quais os professores interpretam, compreendem e orientam o seu trabalho cotidiano.

Concordando com Chartier (2007) e Tardif (201 1), entendemos que a lógica do professor não é e nem poderia ser a mesma do pesquisador. Por isso, é preciso distinguir "coerência teórica" ou "racionalidade científica" de "coerência pragmática" ou "racionalidade docente", que é sempre adequada às situações práticas de exercício do trabalho docente ICHARTIER, 2007; TARDIF, 2001 l). É nessa direção que Tardif esclarece que "[...] os juízos do professor estão voltados para o agir no contexto e na relação com o outro, no 
caso os alunos. Ele não quer conhecer, mas agir e fazer, e, se procura conhecer, é para melhor agir e fazer" (TARDIF, 200 1, p. 200).

Chartier (2007), ao analisar as práticas de ensino da escrita de uma professora do último ano da educação infantil, constatou que as ações dessa docente apoiavam-se em uma coerência pragmática e não teórica. Embora tivesse consciência de que as atividades propostas correspondiam a modelos teóricos distintos, a docente não deixava de desenvolvê-las, considerando que se relacionavam a dimensões particulares da escrita, as quais eram trabalhadas de maneira independente. Nesse sentido,

[...] o que poderia aparecer, de um ponto de vista teórico, como a coexistência heteróclita de atividades evidenciando modelos incompatíveis (tratar a escrita como gesto motor/ como código simbólico/como saber de linguagem específico), aparece, do ponto de vista dos "saberes da ação", como um sistema dotado de uma forte coerência pragmática (não importa o que se possa pensar sobre essa organização) (CHARTIER, 2007, p. 198).

Nos últimos tempos, o interesse dos pesquisadores tem se deslocado, cada vez mais, de uma análise normativa sobre o que os professores deveriam ou não fazer em sala de aula para a compreensão do que eles realmente fazem. Nessa direção, Goigoux (2002) esclarece que, nesse último caso, a atenção recai sobre a descrição dos processos de ensino em sala de aula, a fim de tentar reconstruir as lógicas de ação a eles subjacentes.

Considerando essa perspectiva, assumimos, portanto, a ideia de que as práticas cotidianas dos professores não são resultado de uma transposição didática direta de conhecimentos, seja do âmbito teórico, seja do âmbito das produções especificamente a ele dirigidas, mas, sim, de um processo complexo de (re)invenção que os pesquisadores precisam melhor compreender.

\section{O caminho metodológico da pesquisa}

Nesta pesquisa, adotamos, em consonância com a natureza do objeto e dos objetivos do estudo, uma abordagem qualitativa, que, de acordo com Minayo (201 1), se ocupa do universo de significados, motivos, aspirações, crenças, valores e atitudes. No entanto, como entendermos, assim como 
Práticas de ensino de leitura e escrita no Programa Alfa e Beto: entre estratégias e táticas

essa autora, que não existe dicotomia entre qualidade e quantidade, recorremos também, quando necessário, ao uso de dados quantitativos.

A pesquisa foi realizada em duas salas de aula de duas escolas da rede pública municipal de Caruaru - Pernambuco, que, assim como vários outros munícipios do país, implantaram, à época, o Programa Alfa e Beto de Alfabetização, do Instituto Alfa e Beto. Na rede municipal de ensino da cidade de Caruaru, esse Programa foi adotado nos anos de 2011 e 2012, na educação infantil e nos quatro primeiros anos do ensino fundamental.

Participaram da pesquisa duas professoras de $1^{\circ}$ ano do Ensino Fundamental, que, após alguns contatos iniciais, se dispuseram a colaborar conosco. Para preservar o anonimato das docentes, elas serão denominadas de "professora A" e "professora B". No Quadro 1, apresentado a seguir, tais professoras são caracterizadas:

\section{Quadro 1 | Caracterização das professoras participantes da pesquisa}

\begin{tabular}{|l|l|l|}
\hline \multicolumn{1}{|c|}{ Dados } & \multicolumn{1}{|c|}{ Professora A } & \multicolumn{1}{c|}{ Professora B } \\
\hline $\begin{array}{l}\text { Formação profissional } \\
\text { (curso e ano de conclusão) }\end{array}$ & $\begin{array}{l}\text { Magistério (1990) } \\
\text { Graduação em Ciências } \\
\text { Sociais (2003) } \\
\text { Especialização em em emãa em Pedagogia } \\
\text { Gestão e Supervisão } \\
\text { Escolar (cursando) }\end{array}$ & $\begin{array}{l}\text { Gradua } \\
\text { Especialização } \\
\text { Organização Pedagógica } \\
\text { da Escola - Supervisão } \\
\text { Escolar (cursando) }\end{array}$ \\
\hline $\begin{array}{l}\text { Tempo de experiência } \\
\text { como docente }\end{array}$ & 21 anos & \multicolumn{1}{|c|}{5 anos } \\
\hline $\begin{array}{l}\text { Quantidade de turnos de } \\
\text { trabalho }\end{array}$ & 2 & \multicolumn{1}{|c|}{2} \\
\hline
\end{tabular}

Os dados do Quadro 1 evidenciam que, quanto à formação profissional, as duas professoras tinham habilitação para o magistério nos primeiros anos do ensino fundamental em nível superior (graduação em Pedagogia) e estavam cursando pós-graduação lato sensu (especialização) na área de Educação. Com relação à experiência docente, a professora $A$ era muito mais experiente que a professora $B$, que tinha apenas 5 de trabalho, mas ambas trabalhavam, à época, em dois turnos. 
Para atender ao objetivo da pesquisa, que é analisar as práticas de ensino da leitura e da escrita de professores do Programa Alfa e Beto e com elas se relacionavam ou não com a proposta desse Programa, utilizamos como procedimentos metodológicos a observação participante e a entrevista semiestruturada.

Segundo André (1995, p. 28), "[...] a observação é chamada de participante porque parte do princípio de que o pesquisador tem sempre um grau de interação com a situação estudada, afetando-a e sendo por ela afetado." Tais observações foram realizadas no segundo semestre letivo dos anos de 2011 (professora A) e 2012 (professora B), tendo sido observadas 8 (oito) aulas da professora $\mathrm{A}$ e 10 (dez) aulas da professora $\mathrm{B}^{3}$. $O$ registro dos dados foi feito com o auxílio de dois instrumentos: o diário de campo e a gravação de áudio.

As entrevistas semiestruturadas consistem, segundo Laville e Dione (1999), em uma série de perguntas verbais abertas, em uma ordem prevista, na qual o entrevistador pode acrescentar perguntas de esclarecimento. As entrevistas foram realizadas com gravação de áudio, ao término das observações, e tiveram como objetivo obter dados sobre a formação e experiência profissional das professoras e, principalmente, sobre suas práticas de ensino da leitura e da escrita.

Os dados "brutos", obtidos por meio das observações e entrevistas, foram analisados com o apoio da análise de conteúdo, que contempla, segundo Bardin (2004), processos de descrição, inferência e interpretação. A análise foi desenvolvida por meio de recorte do conteúdo por temas lanálise temática categorial) e envolveu as seguintes etapas indicadas pela autora supracitada: pré-análise, análise do material (codificação e categorização da informação) e tratamento dos resultados, inferência e interpretação.

\section{Análise das práticas de ensino da leitura e da escrita das professoras no âmbito do Programa Alfa e Beto}

Antes de apresentarmos e discutimos os resultados da pesquisa, situaremos o Programa Alfa e Beto de Alfabetização, descrevendo os materiais e as orientações que norteavam o trabalho das professoras investigadas. 
Programa Alfa e Beto de Alfabetização pertence ao Instituto Alfa e Beto (IAB), uma organização não governamental que oferece produtos e serviços voltados para educação infantil, alfabetização e anos iniciais do ensino fundamental. Utiliza o método fônico de alfabetização e é constituído por materiais tanto para uso individual do aluno, quanto para o uso coletivo em sala de aula. São também disponibilizados materiais para os professores, para as escolas e para as secretarias de educação.

O Programa é constituído por materiais como o livro didático "Aprender a Ler", o caderno "Grafismo e Caligrafia: letra cursiva", os "Minilivros", o "Livro Gigante", cartazes, fantoches dos personagens do Programa (Alfa e Beto), cartelas de letras e testes diagnósticos. $\bigcirc$ livro didático "Aprender a Ler", considerado o carro-chefe do Programa, é composto por 20 (vinte) lições e cada uma delas aborda um fonema. As lições são divididas em blocos de atividades: "Leitura", "Brincando com sons e letras"; "Hora de ler"; "Correto?"; "É assim que se escreve"; "Redação"; "Já sei ler".

Conforme o "Manual de Orientação" do Programa, o planejamento das aulas deve ser feito em função de cada lição do livro, que deve ser estudada ao longo de duas semanas, aproximadamente (oito a de dias letivos).

110 Nesse período, o professor deve realizar todas as atividades previstas no livro, assim como as demais atividades que constituem o Programa (cf. OLIVEIRA, 20111 .

Ao analisar as práticas de ensino da leitura e da escrita das professoras alfabetizadoras participantes da pesquisa, percebemos que o uso dos materiais do Programa Alfa e Beto e de outros materiais didáticos ocupavam lugares diferentes na organização de suas rotinas de trabalho. Em outras palavras, cada uma reinventava, à sua maneira, as prescrições do Programa quanto ao uso dos materiais didáticos.

As práticas de ensino da leitura e da escrita da professora $A$ eram organizadas em torno dos materiais didáticos do Programa, principalmente do livro didático, que foi usado em 6 (seis) das 8 (oito) aulas, em consonância com a prescrição anteriormente apresentada. Quando não utilizava esse livro, a docente recorria a outros materiais do Programa ("Minilivros" e "Grafismo e Caligrafia: letra cursiva") e, em apenas uma das aulas, usou outros materiais didáticos, conforme podemos visualizar no Quadro 2: 


\section{Quadro 2 |Materiais didáticos usados pela pro-} fessora A nas aulas observadas

\begin{tabular}{|l|c|c|c|c|c|c|c|c|c|}
\hline \multicolumn{1}{|c|}{ Materiais } & $\begin{array}{c}\mathbf{1}^{\mathbf{a}} \\
\mathbf{a u l a}\end{array}$ & $\begin{array}{c}\mathbf{2}^{\mathbf{a}} \\
\mathbf{a u l a}\end{array}$ & $\begin{array}{c}\mathbf{3}^{\mathbf{a}} \\
\mathbf{a u l a}\end{array}$ & $\begin{array}{c}\mathbf{4}^{\mathbf{a}} \\
\mathbf{a u l a}\end{array}$ & $\begin{array}{c}\mathbf{5}^{\mathbf{a}} \\
\mathbf{a u l a}\end{array}$ & $\begin{array}{c}\mathbf{6}^{\mathbf{a}} \\
\mathbf{a u l a}\end{array}$ & $\begin{array}{c}\mathbf{7}^{\mathbf{a}} \\
\mathbf{a u l a}\end{array}$ & $\begin{array}{c}\mathbf{8}^{\mathbf{a}} \\
\mathbf{a u l a}\end{array}$ & Total \\
\hline Aprender a ler & $X$ & & & $X$ & $X$ & $X$ & $X$ & $X$ & 6 \\
\hline Minilivros & & & $X$ & & & & & & 1 \\
\hline $\begin{array}{l}\text { Grafismo e caligra- } \\
\text { fia: letra cursiva }\end{array}$ & & $X$ & & $X$ & & & & & 2 \\
\hline Outros & & $X$ & & & & & & & 1 \\
\hline
\end{tabular}

Já as práticas de ensino da leitura e da escrita da professora B, apesar de também terem o livro didático e outros materiais do Programa como eixo, eram marcadas pelo uso sistemático - em 7 (sete) das 10 (dez) aulas - de materiais que não faziam parte do Programa, conforme podemos visualizar no Quadro 2, a seguir. Inclusive, em 3 (três) das 10 (dez) aulas, a docente não utilizou nenhum material do Programa.

Quadro 3 | Materiais didáticos usados pela professora B nas aulas observadas

\begin{tabular}{|c|c|c|c|c|c|c|c|c|c|c|c|}
\hline Material & $\begin{array}{l}1^{\mathrm{a}} \\
\text { aula }\end{array}$ & $\begin{array}{l}2^{\mathrm{a}} \\
\text { aula }\end{array}$ & $\begin{array}{l}3^{a} \\
\text { aula }\end{array}$ & $\begin{array}{l}4^{a} \\
\text { aula }\end{array}$ & $\begin{array}{l}5^{a} \\
\text { aula }\end{array}$ & $\begin{array}{l}6^{a} \\
\text { aula }\end{array}$ & $\begin{array}{l}7^{a} \\
\text { aula }\end{array}$ & $\begin{array}{l}8^{a} \\
\text { aula }\end{array}$ & $\begin{array}{l}9^{a} \\
\text { aula }\end{array}$ & $\begin{array}{l}10^{\circ} \\
\text { aula }\end{array}$ & Total \\
\hline $\begin{array}{l}\text { Aprender } \\
\text { a ler }\end{array}$ & $x$ & & & $x$ & & & $x$ & $x$ & $x$ & & 5 \\
\hline Minilivros & & & $x$ & & & & & & $x$ & $x$ & 3 \\
\hline $\begin{array}{l}\text { Alfabeto } \\
\text { móvel }\end{array}$ & $X$ & & & & & & & & & & 1 \\
\hline Outros & $x$ & $x$ & $x$ & & $x$ & $x$ & $x$ & & & $x$ & 7 \\
\hline
\end{tabular}

uso dos materiais do Programa e de outros recursos didáticos pelas professoras estava relacionado a diferentes aspectos. Enquanto a professora A sinalizou, durante a entrevista, que gostava dos materiais didáticos do Programa, pois eles apresentavam um conjunto de atividades que pareciam 
facilitar a organização cotidiana de suas práticas de ensino da leitura e da escrita, a professora B, por sua vez, demonstrou insatisfação em relação a esses mesmos materiais, seja porque apresentavam atividades repetitivas, que deveriam ser realizadas, seja porque eram consumíveis e estavam sendo reutilizados ${ }^{4}$ :

Assim, o bom é que vem as atividades, não é? A gente tem o livro, a gente tem o caminho. Chega naquele dia, sabe o que vai fazer. E também tem o planejamento de 15 em 15 dias, que a gente faz daquela semana. Aí trabalha aquelas duas semanas, depois volta, faz de novo, e revê o que foi que fez. [...] Cada dia tem uma atividade. Tem a atividade de leitura, a leitura do professor, a leitura depois das palavras, e depois o bloco 'Correto' e o auxílio dos 'Minilivros' (PROFESSORA A, 2011 ).

[...] aqui no Programa eu acho tudo muito mecanizado. A gente tem que seguir o livro [...] é assim e é desse jeito que você tem que fazer. [...] Às vezes, com o Programa, fica tão, muito assim, a mesma coisa. Todo dia a mesma coisa: leitura, ditado, fazer um texto através de imagem. Toda lição, a mesma coisa. São vinte lições. Em cada lição, você tem que trabalhar do mesmo jeito. [...] Até eles (os alunos), às vezes, não ficam nem aí pra fazer (PROFESSORA B, 2012).

Para analisar mais detidamente as práticas de ensino da leitura e da escrita dessas professoras, discutiremos, em um primeiro momento, os usos que elas faziam dos materiais do Programa, para, em seguida, debruçarmo-nos sobre a utilização de outros recursos didáticos.

\section{Práticas de ensino da leitura e da escrita com o uso de materiais didáticos do Programa Alfa e Beto}

Nesta seção, analisaremos as práticas de ensino da leitura e escrita com uso de materiais didáticos do Programa a partir das maneiras diferentes pelas quais as orientações que envolviam o trabalho com fonemas eram tratadas pelas professoras.

Ao longo das observações, percebemos que a professora $A$, a despeito da orientação do Programa, não ensinava os alunos a pronunciar os fonemas e a uni-los para formar palavras. Em vez disso, usava os nomes das 
letras para se referir a eles (os fonemas). Em uma das aulas, conforme podemos observar no extrato de aula apresentado a seguir, essa docente desenvolveu uma atividade (Figura 1) que solicitava aos alunos bater palmas quando ouvissem o fonema / $t$ / em diferentes posições em palavras lidas por ela. No entanto, ela o substitui pelo nome da letra a que ele se refere, não o pronunciando em momento algum.

\section{Figura 1 | Atividade do Livro "Aprender a Ler"}

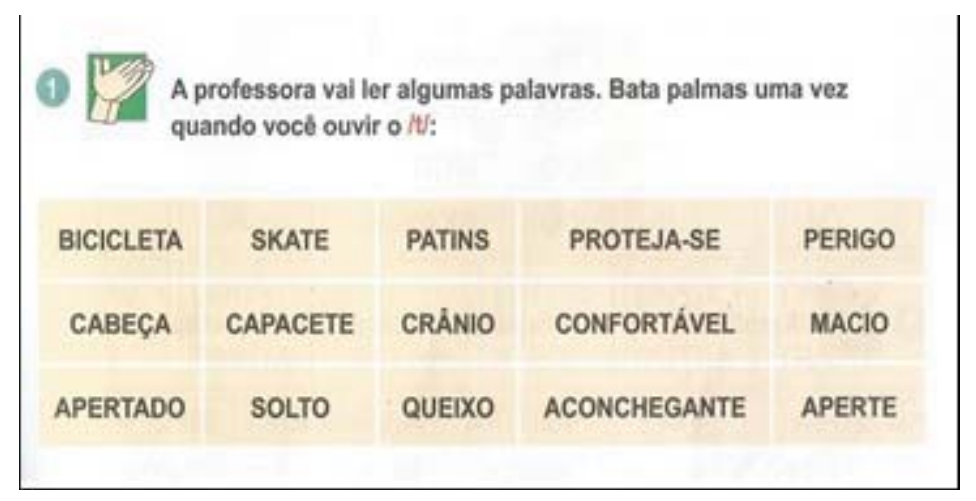

Fonte | Oliveira e Castro, 2010

$\mathrm{PA}^{5}$ - A professora vai ler algumas palavras. Bata palmas uma vez quando você ouvir que letrinha? (a professora lê o enunciado da atividade, substituindo o fonema pela expressão "que letrinha").

A - A (responderam alguns alunos).

PA - O quê? Qual?

$A-B$ (responderam os alunos)

PA - Qual? Não é B não, eu não escutei B não.

A - O T (respondeu um aluno).

PA - É essa aqui, oh! (a professora aponta para um cartaz que continha o alfabeto e indica a letra T).

PA - Como é o nome dela?

A - T (responderam os alunos).

A-É OT.

(AULA 1, PROFESSORA A, 2011 )

Essa "tática de consumo" (CERTEAU, 2012) de dizer os nomes das letras em vez de pronunciar os fonemas isoladamente também foi observada 
Práticas de ensino de leitura e escrita no Programa Alfa e Beto: entre estratégias e táticas

em outros estudos, como os de Aragão (2013), Moraes (2013) e Silva e Silva (2013), e parece estar relacionada a dois aspectos articulados: a complexidade, para as crianças e para as próprias professoras, da pronúncia de fonemas isolados e a maior familiaridade das docentes com a alfabetização por meio de letras e/ou sílabas e não de fonemas.

Quanto ao primeiro aspecto, dispomos, atualmente, de evidências de que a capacidade de segmentar palavras em fonemas, pronunciando-os um a um em voz alta, não é condição necessária ou requisito para a aprendizagem da leitura e da escrita. Morais (2013) evidenciou que, mesmo crianças com hipótese alfabética, ensinadas pelo método fônico, não conseguiam resolver tarefas de consciência fonêmica, como segmentar e pronunciar fonemas. As análises qualitativas dos acertos e erros dessas crianças revelaram, ainda, que elas tendiam a pensar sobre letras ou sílabas e não sobre fonemas.

Ao analisar a trajetória histórica dos métodos na prática escolar, Braslavsky (1988) observa que os métodos fônicos surgiram para superar a soletração, mas, apesar de suas vantagens em relação a estes, cedo foram percebidas também suas desvantagens, as quais deram lugar ao aparecimento dos métodos silábicos: "[...] a dificuldade para pronunciar as consoantes iso114 ladas, para uni-las com as vogais e para estabelecer a correspondência entre cada letra do alfabeto escrito e os fonemas da linguagem falada" (BRASLAVSKY, 1988, p. 431.

É interessante destacar que, quando desenvolvia a atividade de reconhecimento de fonemas em diferentes posições em palavras, a professora A indicava as respostas aos alunos, levantando a mão sempre que a palavra lida possuía o fonema estudado, conforme podemos observar no trecho abaixo, que é uma continuação do anterior:

PA - Então eu vou falar a palavra. Se eu levantar a mão, o quê que vocês vão fazer?

PA - Quando eu fizer assim (levantou a mão), vocês batem.

PA - Bicicleta (levantou a mão e as crianças bateram palmas).

(AULA 1, PROFESSORA A, 2011 )

Esse procedimento de indicar e/ou induzir as respostas das atividades estava presente em diferentes momentos das aulas dessa professora. Quando isso ocorria, pareciam estar em jogo dois aspectos articulados: de um lado, a exigência do Programa de cumprimento do cronograma de lições e de 
realização de todas as atividades do livro didático. De outro, o nível de complexidade de algumas atividades para os alunos, que não tinham condições de respondê-las, sem errar. Diante desse impasse, a solução encontrada pela professora parece ter sido a de responder, ela mesma, as atividades ou induzir as respostas.

Quanto à maior familiaridade das professoras com a alfabetização por meio de letras e/ou sílabas e não de fonemas, consideramos que a silabação e soletração parecem ter tido um maior impacto no cotidiano das classes de alfabetização, permanecendo, até os dias atuais, no repertório de práticas de muitos professores, principalmente daqueles que contam um maior tempo de experiência de ensino, como a professora A, que tinha mais de 20 (vinte) anos de atuação docente.

$O$ trabalho com letras e não com fonemas pode ser percebido também nas práticas da professora A quando ela solicitava aos alunos, em algumas aulas, a identificação de letras, geralmente em textos do livro didático. Segundo a docente, apesar dessa atividade não ser indicada pelo Programa, ela a utilizava para ajudar os alunos a reconhecer o grafema estudado em cada lição, o que atesta, mais uma vez, o trabalho no nível da letra e não do fonema, conforme podemos observar nos extratos a seguir:

PA - Vocês vão pegar... Primeira coisa, antes de pintar... Pode ser com o lápis de cor ou o de escrever. Vocês vão circular toda vez que vocês encontrarem o T. Aí circula o T. Primeira coisa antes de pintar. Aí depois pode pintar. Assim, oh (a professora escreveu no quadro a letra T minúscula e maiúscula e circulou-as) (AULA 3, PROFESSORA A, 20111.

Ao chegar do recreio, a professora pediu para que os alunos pegassem novamente o livro e pintasse todas as letras $G$ que encontrassem no texto lido (AULA 4, PROFESSORA A, 2011 ).

P- Peguem agora um lápis de cor. Pode ser qualquer cor. É pra pintar todas as letrinhas $G$ que vocês encontrarem no "escorregar o dedo6 (AULA 7, PROFESSORA A, 2011 ).

Diferentemente da professora A, a professora B seguia as orientações do Programa, pronunciando o fonema que estava sendo ensinado e solicitando às crianças que também realizassem esse mesmo procedimento. Apesar disso, observamos, mais de uma vez, as crianças mencionarem os nomes das letras e não os fonemas, conforme podemos observar no extrato de aula abaixo, no 
qual os alunos foram solicitados a bater palmas quando ouvissem o fonema $/ \mathrm{i} /$ :

PB: E aí, a gente vai fazer o que? Leiam pra mim las crianças leram a questão, depois a professora leu novamente).

PB - Qual o som dessa letra aqui? (apontando para o J).

A: J (dizem o nome da letra).

PB: Como é o som do J? Esse é o nome. E o som? É /i/.

A: /i/

PB: A primeira palavra, "ACHO", tem o som de /i/?

A: Não.

(AULA 4, PROFESSORA B, 2012).

As orientações quanto ao trabalho com fonemas foram, portanto, recebidas e/ ou usados de maneiras diferentes pelas professoras, as quais também recorreram, como veremos na seção a seguir, a outros materiais que não faziam parte do Programa, os quais se relacionavam a outras perspectivas teórico-metodológicas.

\section{Práticas de ensino da leitura e da escrita sem o uso de materiais do Programa Alfa e Beto}

Como vimos anteriormente, as professoras, sobretudo a $B$, usaram em suas aulas, apoiando-se em uma "tática de consumo" (CERTEAU, 2012), materiais que não faziam parte do Programa Alfa e Beto. Nessas situações, elas não recorriam ao método fônico, mas, sim, a atividades que se apoiavam, principalmente, na exploração de letras e sílabas.

Em duas aulas observadas, conforme percebemos no Quadro 1, a professora A não utilizou o livro didático, embora tenha recorrido a outros materiais do Programa (minilivros e caderno de caligrafia). Em uma delas, que consistia em uma revisão das lições já estudadas, a docente usou a atividade apresentada a seguir, que envolve o trabalho com letras e, principalmente, sílabas: 


\section{Figura 2 | Atividade usada pela professora A}

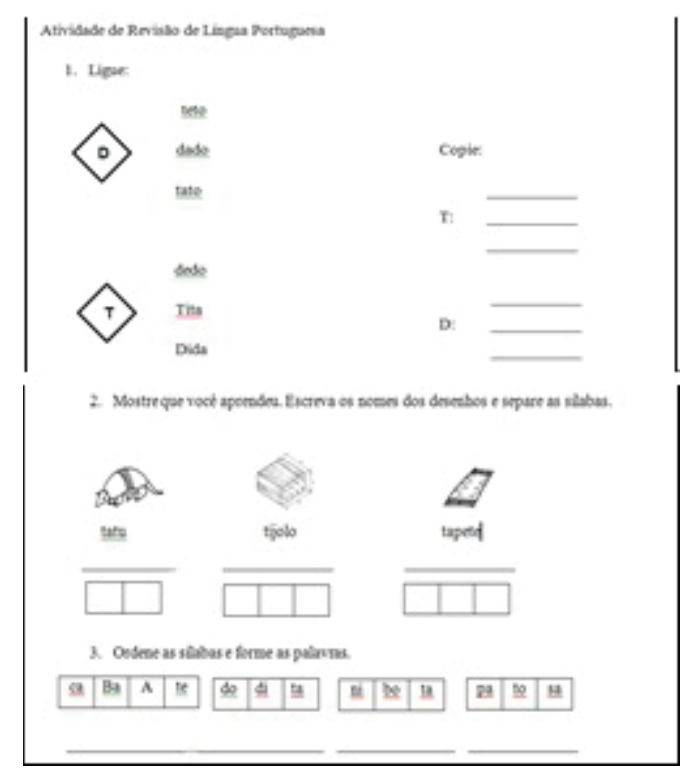

Fonte | Elaborado pela professora A

Ao longo das observações, percebemos a utilização, pela professora

A, de algumas maneiras de fazer relacionadas ao método silábico, cujo procedimento de ensino característico é a combinatória de sílabas para constituição de palavras, frases etc. Tais "artes de fazer" (CERTEAU, 2012) referiam-se à maneira como ela realizava a leitura e o ditado de palavras com os alunos. No primeiro caso, ela lia sílaba por sílaba e, em seguida, a palavra inteira, acompanhada pela repetição dos alunos, como podemos visualizar a seguir no extrato de observação:

PA - Ficou como? Ti-to, ta-to, Ti-ta (leu a professora).

PA - E essa daqui? Da-do, de-do, di-ta (leu a professora).

PA - Leiam novamente. Aqui ficou como? Três palavrinhas para cada letra. Novamente: te-to, teto. Ta-to, tato. Ti-ta, Tita. la professora lia e as crianças repetiam).

PA - Agora com o D. Da-do, dado. De-do, dedo. Di-ta, dita.

PA - Novamente: te-to, teto. Ta-to, tato. Ti-ta, Tita. Da-do, dado. De-do, dedo. Di-ta, Dita. (a professora lia e as crianças repetiam) (AULA 2, PROFESSORA A, 2011 ). 
No caso do ditado, a professora, inicialmente, escrevia no quadro todas as famílias silábicas já estudadas e que seriam utilizadas no ditado. Quando ditava a palavra, apontava a sílaba pronunciada com uma régua. Por exemplo, se a lição do livro estivesse abordando o fonema / $\mathrm{p} /$, ela escrevia no quadro, antes de ditar, a família silábica dessa letra $(\mathrm{PA}, \mathrm{PE}, \mathrm{Pl}, \mathrm{PO}, \mathrm{PU}$, $P \tilde{A}$ |, e, ao ditar a palavra "PIPA", por exemplo, apontava com a régua as sílabas PI e PA, indicado as respostas, conforme mencionamos anteriormente.

Quando questionamos a professora sobre a realização de propostas diferentes daquelas do Programa, ela informou que, às vezes, utilizava atividades de um material didático chamado "Tin-do-lê-lê"7, que, segundo ela, era semelhante ao do "Alfa e Beto", mas se tratava de um método silábico, e não fônico. Esse dado parece confirmar que o método silábico teve maior influência na constituição das práticas de alfabetização dessa professora, porque ela recorria a ele quando propunha atividades extras, mesmo estando participando de um Programa que usava o método fônico.

Na maioria das aulas observadas, percebemos que a professora $B$ também fazia uso de outros materiais, entre eles o livro didático Porta Aberta, de Isabella Carpaneda e Angiolina Bragança ${ }^{8}$, além de atividades que, 118 segundo a docente, foram retiradas da internet. Embora atendesse, na maioria das vezes, às orientações do Programa ao abordar os fonemas, as atividades adicionais propostas por ela costumavam contemplar o nível da sílaba, incluindo, às vezes, famílias silábicas. Eis um exemplo: 


\section{Figura 3 | Atividade usada pela professora B}

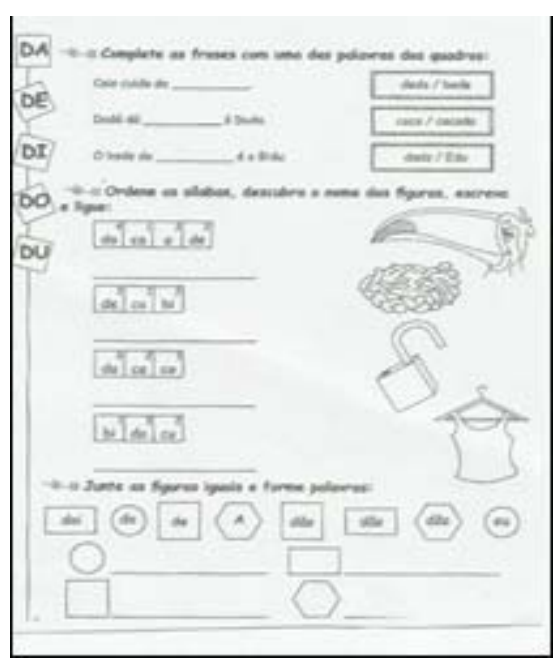

Fonte | Elaborado pela professora B

Quando perguntamos se essa docente já havia lecionado em turmas de alfabetização antes de participar do Programa Alfa e Beto, ela respondeu que sim e disse que alfabetizava a partir da letra e não do fonema. Como em várias cartilhas do método silábico geralmente são apresentadas uma letra e uma palavra-chave, esta última utilizada apenas para apresentar as famílias silábicas (FRADE, 2007), acreditamos que a docente estava se referindo ao uso de um manual silábico, que, a cada lição, evidenciava uma letra para, a partir dela, apresentar a família silábica correspondente. Eis o que ela disse:

Assim, a gente trabalhava os fonemas, mas numa ordem diferente, que era a ordem do alfabeto. Aí trabalhava mais a questão da letra mesmo. Aí no caso não era o fonema, era o grafema (PROFESSORA B, 2012).

No caso da professora B, existiam, ainda, outras atividades que ela realizava com textos de diferentes gêneros que não faziam parte do Programa Alfa e Beto. Em cada mês, um gênero era abordado por ela em sala de aula: no mês de agosto, o gênero selecionado foi a "receita culinária", cujo trabalho culminou com a montagem de um livro de receitas retiradas de embalagens de alimentos; no mês de setembro, o gênero "fábula", que, ao final do período, foi transformado em peça teatral e apresentado para toda a escola; no mês 
de outubro, o gênero "entrevista", quando as crianças entrevistaram diferentes membros da escola e da comunidade. Essa proposta constituía uma iniciativa da própria escola na qual a professora atuava e não uma orientação do Programa. Eis um extrato de aula a título de ilustração:

Ao retornarem do intervalo, a professora explicou que no mês de outubro o gênero trabalhado seria a entrevista. Em seguida, ela questiona as crianças sobre o que é uma entrevista e onde podemos encontrá-la (revistas, jornais, televisão, rádio). Após esse momento, uma das alunas veio entrevistar a bolsista de iniciação científica que observava a aula: a aluna leu as perguntas para a bolsista e anotou as respostas dadas por ela no caderno. Enquanto isso, outro aluno fingia ser o 'câmera' que estava filmando a entrevista e os demais alunos assistiam a tudo em silêncio (AULA 7, PROFESSORA B, 2012).

Além do trabalho com diferentes gêneros textuais a cada mês, as crianças, uma vez por semana, tinham acesso ao acervo de livros infantis da biblioteca da sede da escola9. Nesse dia, a bibliotecária levava até o anexo uma caixa de livros, que as crianças podiam ler à vontade e, inclusive, fazer 120 empréstimos, levando-os para ler com seus familiares, em casa. Para isso, possuíam uma "carteirinha de leitor", com a data de empréstimo e devolução. Os livros eram variados: com muitas ou poucas ilustrações, de diferentes formas e tamanhos e continham, por exemplo, histórias, poemas ou histórias em quadrinhos.

É possível constatar, portanto, nas práticas de ensino da leitura e da escrita dessa docente, tentativas de inserir os alunos em práticas letradas de leitura, ao possibilitar que eles tivessem contato com textos de circulação social, os quais se distinguiam da maioria absoluta dos pseudotextos apresentados pelo Programa, que continham léxico extremamente controlado, incluindo, apenas, palavras com os fonemas já estudados e as vogais, e frases justapostas, conforme podemos observar no exemplo a seguir: 


\section{Figura 4 | Exemplo de pseudotexto do livro "Aprender a Ler"}

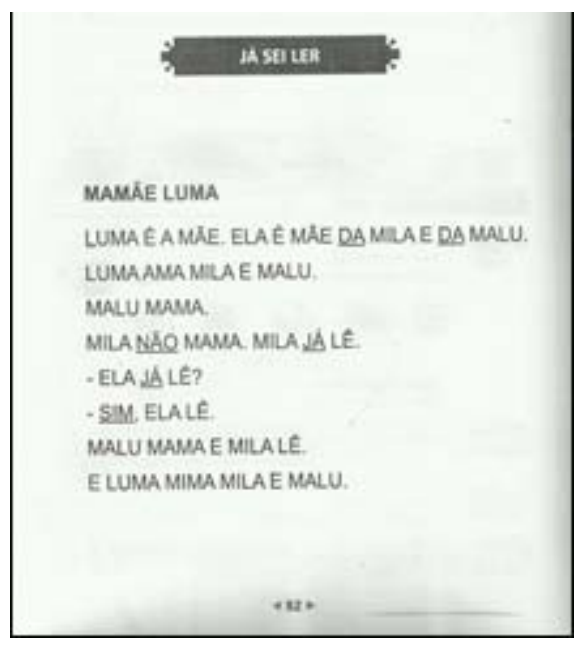

Fonte | Oliveira e Castro, 2010

Podemos constatar, portanto, que as práticas de ensino da leitura e da escrita das docentes participantes da pesquisa caracterizavam-se por um movimento no qual algumas ações eram voltados a atender às exigências do Programa, enquanto outras se distanciavam das orientações e prescrições dele.

\section{Considerações finais}

Os resultados deste estudo evidenciaram que as práticas de ensino da leitura e da escrita das professoras eram, de modo geral, organizadas em torno dos materiais didáticos do Programa Alfa e Beto, principalmente do livro didático, conforme a prescrição desse Programa. Apesar disso, percebemos que elas (re)inventavam, em seu cotidiano, outras maneiras de fazer, como dizer o nome das letras em vez de pronunciar os fonemas e acrescentar outras propostas e materiais, alguns deles mais próximos do método silábico e outros relacionados à perspectiva do letramento.

Esses dados evidenciam, portanto, que as professoras, mesmo estando submetidas à orientação de seguir o Programa, à risca, construíam suas práticas de ensino da leitura e da escrita pautando-se não apenas nas orientações e materiais do programa, mas também em outros materiais e em 
outras experiências que vivenciaram e que constituíam os seus saberes e as suas práticas.

Inspirando-nos em Certeau (2012), podemos dizer que os professores (re)inventam suas práticas de ensino a partir de "táticas". Em outras palavras, aproveitando a sua "margem de manobra", modificam as "estratégias" e constroem maneiras de fazer que não correspondem às prescrições, mas que se coadunam ao seu trabalho cotidiano. Tal como observa Chartier, "Estas 'artes de fazer' mostram-se inventivas, bricolagens, engenhosas, pois é preciso sempre gerar contradições insolúveis, inventar compromissos, responder a situações tanto urgentes quanto imprevisíveis" (CHARTIER, 2005, p. 24).

Em suma, essa multiplicidade de práticas de ensino de leitura e escrita que não cabem em "um" método de alfabetização impõe, segundo Goigoux e Cèbe (2006), a necessidade de reconsiderarmos a dicotomia entre métodos, que oculta a diversidade de respostas apresentadas no cotidiano pelos professores, as quais não podem ser vistas em "preto" ou "branco", mas em um "dégradé" de tons de cinza.

\section{Notas}

1 Este artigo apresenta resultados de pesquisa desenvolvida com auxílio financeiro do CNPq e apoio da FACEPE, que concedeu bolsas de iniciação científica às alunas Estephane Priscilla dos Santos Mendes e Ridelma Barbosa de Moura.

2 O termo "tradicional" é usado neste artigo para caracterizar um conjunto de práticas de ensino de leitura e escrita que, por terem se consolidado ao longo do tempo, constituíram uma tradição no campo da alfabetização.

3 Não foi possível observar o mesmo número de aulas das duas docentes, devido a algumas dificuldades de ordem operacional.

4 As observações na sala de aula dessa professora foram realizadas no segundo ano de implantação do Programa, quando os materiais didáticos estavam sendo reutilizados.

5 Nos extratos de aula, usaremos PA e PB para indicar as falas das professoras e A para as falas dos alunos.

6 Trata-se de uma atividade do livro didático do Programa que envolve leitura de palavras e chama-se "leia emendando".

7 Esse material didático intitula-se "Alfabetização Silábica Tin-do-lê-lê" e está dividido em quatro cadernos de atividades: vogais, alfabeto $B$ a $G$, alfabeto $H$ a $R$ e alfabeto $S$ a $Z$ (informações disponíveis em: http://produto.mercadolivre.com.br/ MLB-5475 1 1277-alfabetizaco-silabica-tin-do-le--1 ano-5-a-6-anos-JM). 
8 Segundo o Guia de Livros Didáticos do PNLD 2013, a proposta de ensino do sistema de escrita alfabética desse livro privilegia modelos de atividades de ordenamento e complemento de sílabas e letras em palavras (BRASIL, 2012, p. 122).

9 Essa professora atuava em um anexo de uma escola.

\section{Referências}

ANDRÉ, Marli. Ełnografia da prática escolar. São Paulo: Papirus, 1995.

ARAGÃO, Sílvia de Souza. O método fônico "Alfa e Beto": o que dizem sobre ele professoras de uma rede municipal? In: CONGRESSO BRASILEIRO DE ALFABETIZAÇÃO, 1 ; 2013 , Belo Horizonte. Anais... Marília: Associação Brasileira de Alfabetização, 2013. CD-ROM.

AULA 1, Professora A, Caruaru (Pernambuco), 10 nov. 2011.

AULA 2, Professora A, Caruaru (Pernambuco), 17 nov. 2011.

AULA 3, Professora A, Caruaru (Pernambuco), 21 nov. 2011.

AULA 4, Professora A, Caruaru (Pernambuco), 23 nov. 2011.

AULA 7, Professora A, Caruaru (Pernambuco), 29 nov. 2011.

AULA 4, Professora B, Caruaru (Pernambuco), 17 set. 2012.

AULA 7, Professora B, Caruaru (Pernambuco), 1 out. 2012.

BRASIL. Guia de livros didáticos: PNLD 2013: letramento e alfabetização e língua portuguesa. Brasília: Ministério da Educação, Secretaria de Educação Básica, 2012.

BRASLAVSKY, Berta. O método: panaceia, negação ou pedagogia? Cadernos de Pesquisa, São Paulo, n. 66, p. 41-48, ago. 1988.

BARDIN, Laurence. Análise de conteúdo. 3. ed. Tradução Luís Antero Reto e Augusto Pinheiro. Lisboa: Edições 70, 2004.

CERTEAU, Michel de. A invenção do cotidiano. 19. ed. Tradução Ephrain Ferreira Alves. Petrópolis: Vozes, 2012.

CHARTIER, Anne-Marie. Escola, culturas e saberes. In: XAVIER, Libânia Nacif; CARVALHO, Marta Maria Chagas; MENDONÇA, Ana Valeska; CUNHA, Jorge Luiz (Org.). Escola, culturas e saberes. Rio de Janeiro: FGV, 2005. 
Práticas de ensino de leitura e escrita no Programa Alfa e Beto: entre estratégias e táticas

CHARTIER, Anne-Marie. Réussite, échec et ambivalence de l'innovation pédagogique : le cas de l'enseignement de la lecture. Recherche et Formation, Paris, n. 34, p. 41-56, décembre 2000.

CHARTIER, Anne-Marie. A ação docente: entre saberes práticos e saberes teóricos. In: CHARTIER, Anne-Marie. Práticas de leitura e escrita: história e atualidade. Tradução Flávia Sarti e Teresa Van Acker. Belo Horizonte: Ceale/Autêntica, 2007.

CHARTIER, Anne-Marie; HEBRARD, Jean. Méthode syllabique et méthode globale: quelques clarifications historiques, Le Français aujourd'hui, Paris, n. 90, p. 100-109, juin 1990.

FERREIRO, Emilia. Reflexões sobre alfabetização. 23. ed. Tradução Horácio Gonzales, Maria Amélia de Azevedo Goldeberg, Maria Antônia Cruz Costa Magalhães, Mansa do Nascimento Paro e Sara Cunha Lima. São Paulo: Cortez, 1995.

FERREIRO, Emilia; TEBEROSKY, Ana. Psicogênese da língua escrita. Tradução Diana Myriam Litchtenstein, Liana Di Marco e Mário Corso. Porto Alegre: Artes Médicas, 1999.

FRADE, Isabel Cristina. Métodos de alfabetização, métodos de ensino e conteúdos da alfabetização: perspectivas históricas e desafios atuais. Educação, Santa Maria, v. 32, n. 1, p. $21-40$, jan./jun. 2007.

124 GOIGOUX, Roland; CÉBE, Sylvie. Apprendre à lire à l'école: tout ce qu'il faut savoir pour accompagner l'enfant. Paris: Retz, 2006.

GOIGOUX, Roland. Analyser l'activité d'enseignement de la lecture: une monographie. Revue Française de Pédagogie, Paris, n. 138, p. 125-134, janvier/mars 2002.

LAVILLE, Christian; DIONNE, Jean. A construção do saber: manual de metodologia da pesquisa em ciências humanas. Tradução Heloísa Monteiro e Francisco Settineri. Porto Alegre: Artmed; Belo Horizonte: Editora UFMG, 1999.

MINAYO, Maria Cecília de Souza. O desafio da pesquisa social. In: MINAYO, Maria Cecília de Souza (Org.). Pesquisa social: teoria, método e criatividade. 30. ed. Petrópolis, RJ: Vozes, 2011.

MORAES, Daisinalva Amorim de. A fabricação de práticas de ensino de leitura e da escrita: o que dizem as professoras. In: CONGRESSO BRASILEIRO DE ALFABETIZAÇÃO, 1 ; 2013. Belo Horizonte. Anais... Marília: Associação Brasileira de Alfabetização, 2013. 1 CD-ROM. MORAIS, Artur Gomes de. Crianças com hipótese alfabética, ensinadas pelo método fônico, não conseguem resolver tarefas de consciência fonêmica. In: CONGRESO LATINOAMERICANO PARA O DESARROLLO DE LA LECTURA Y LA ESCRITURA Y IV FORO 
IBEROAMERICANO DE LITERACIDAD Y APRENDIZAJE, 7.; 2013. Puebla. Anais... Puebla: Red de Cultura Escrita y Comunidades Discursivas, 2013. 1 CD-ROM.

MORTATTI, Maria do Rosário Longo. Alfabetização no Brasil: conjecturas sobre as relações entre políticas públicas e seus sujeitos privados. Revista Brasileira de Educação, Rio de Janeiro, n. 44, v. 15, p. 329-341, maio/ago. 2010.

MORTATTI, Maria do Rosário Longo. Os sentidos da alfabetização: São Paulo - 1876 / 1994. São Paulo: UNESP; Brasília: MEC/INEP/COMPED, 2000.

OlIVEIRA, João Batista Araújo e. Manual de orientação do Programa Alfa e Beto. 10. ed. Brasília: Instituto Alfa e Beto, 2011.

OLIVEIRA, João Batista Araújo e; CASTRO, Juliana Cabral Junqueira de. Aprender a ler. 2. ed. Brasília: Instituto Alfa e Beto, 2010.

PROFESSORA A. Entrevista. Caruaru (Pernambuco), 2 dez. 2011.

PROFESSORA B. Entrevista. Caruaru (Pernambuco), 10 nov. 2012.

SARTI, Flávia Medeiros. $\bigcirc$ professor e as mil maneiras de fazer no cotidiano escolar. Educação: teoria e prática, Rio Claro/SP, v. 18, n. 30, p. 47-65, jan./jun. 2008.

SILVA, Nayanne Nayara Torres; SILVA, Alexsandro da. Uso do livro didático "Aprender a ler" do Programa Alfa e Beto de Alfabetização: o que fazem as professoras?. In: CONGRESO LATINOAMERICANO PARA O DESARROLLO DE LA LECTURA Y LA ESCRITURA Y IV FORO IBEROAMERICANO DE LITERACIDAD Y APRENDIZAJE, 7.; 2013 . Puebla. Anais... Puebla: Red de Cultura Escrita y Comunidades Discursivas 2013. CD-ROM.

SOARES, Magda. Alfabetização e letramento. 2. ed. São Paulo: Contexto, 2004.

SOARES, Magda. Letramento e alfabetização: as muitas facetas. Revista Brasileira de Educação, Rio de Janeiro, n. 25, p. 5-17, jan./abr. 2004a.

SOARES, Magda. Letramento: um tema em três gêneros. Belo Horizonte: Autêntica, 1998.

TARDIF, Maurice. Saberes docentes e formação profissional. 12. ed. Tradução Francisco Pereira. Petrópolis, RJ: Vozes, 2011.

WEISSER, Marc. Le savoir de la pratique: I'existence précède l'essence... Recherche et Formation, Paris, n. 27, p. 93-102, décembre, 1998. 
Artigo

Práticas de ensino de leitura e escrita no Programa Alfa e Beto: entre estratégias e táticas

Prof. Dr. Alexsandro da Silva Universidade Federal de Pernambuco Centro Acadêmico do Agreste | Caruaru | Pernambuco Núcleo de Formação Docente Programa de Pós-Graduação em Educação Contemporânea Centro de Estudos em Educação e Linguagem Grupo de Pesquisa Didática da Língua Portuguesa E-mail | alexs-silva@uol.com.br

Recebido 7 abr. 2014 Aceito 24 maio. 2014 